ISSN 0103-5150

Fisioter. Mov., Curitiba, v. 29, n. 3, p. 543-552, Jul./Set. 2016

Licenciado sob uma Licença Creative Commons

DOI: http://dx.doi.org.10.1590/1980-5918.029.003.A012

\title{
Tai-chi-chuan and yoga onpostexercise hypotension: comparison to aerobic and resistance exercise
}

\author{
Hipotensão pós-exercício em Tai-chi-chuan e Yoga: \\ Comparação com exercício aeróbio e resistido
}

João Douglas Alves ${ }^{[a]}$, Jorge Luiz de Brito Gomes ${ }^{[a, b]}$, Caio Victor Coutinho de Oliveira ${ }^{[\mathrm{c}]}$, José Victor de Miranda Henriques Alves ${ }^{[a]}$, Fabiana Ranielle de Siqueira Nogueira ${ }^{[a]}$, Aline de Freitas Brito ${ }^{[\mathrm{d}]^{*}}$

[a] Universidade Federal da Paraíba (UFPB), João Pessoa, PB, Brazil

[b] Universidade de Pernambuco (UPE), Recife, PE, Brazil

[c] Faculdade Maurício de Nassau (UNINASSAU), Recife, PE, Brazil

[d] Universidade Federal do Piauí (UFPI), Teresina, PI, Brazil

\section{Abstract}

Introduction: Tai-Chi-Chuan and Yoga have becoming popular practices. However is unclear the cardiovascular effects, and if they present similar behavior to aerobic and resistance sessions. Objective: To evaluate the cardiovascular responses during the session and post-exercise hypotension (PEH) of Tai Chi Chuan (TS) and Yoga (YS) in comparison to aerobic (AS) and resistance (SR) exercises. Methods: Fourteen young women (22.3 \pm 2 years) apparently healthy performed four sessions (AS, RS, TS and YS). The heart rate (HR), systolic (SBP) and diastolic blood pressure (DBP) were recorded at resting, during (every 10 minutes) and until 50 minutes of recovery. Results: AS, RS, TS e YS showed significant increase in HR compared to resting.

\footnotetext{
*JDL: BS, e-mail: douglas.jd10@gmail.com JLBG: Doctoral Student, e-mail: jorgelbritog@hotmail.com CVCO: MS, e-mail: caiovco@gmail.com JVMHA: BS, e-mail: josevictor@hotmail.com FRSN: BS, e-mail: rany.nadadora@bol.com.br AFB: PhD, e-mail: alineebritoo@gmail.com
} 
AS at 10, 30 e 50 minutes in relation to RS, TS e YS. The RS in relation to TS and YS at 10, 30 and 50 minutes. No significant difference between TS and YS. SBP was significantly increased in AS, RS, TS e YS at 10, 30 e 50 minutes during the session, in relation to rest. AS was significantly higher at 30 e 50 minutes than RS and higher than TS and YS at 10, 30 e 50 minutes. No significant difference in DBP. For PEH, AS, RS and TS significantly reduced at 10, 30 and 50 minutes. YS reduced at 50 minutes. No significant diastolic PEH. Conclusion: TS and YS showed as safe alternatives of exercising in the normotensive young adult woman, despite having lower values, they promote similar hemodynamic behavior to AS and RS.

Keywords: Tai Ji. Yoga. Exercise. Physical Fitness. Hypotension.

\section{Resumo}

Introdução: Tai-Chi-Chuan e Yoga vem se tornando práticas populares. No entanto não está claro os efeitos cardiovasculares e se apresentam comportamento similar às sessões aeróbicas e resistidas. Objetivo: Avaliar as respostas cardiovasculares durante a sessão e hipotensão pós-exercício (HPE) de Tai Chi Chuan (TS) e Yoga (YS) comparando com sessões aeróbica (AS) e resistida (RS). Métodos: Catorze mulheres jovens (22,3 2 anos), aparentemente saudáveisrealizaram quatro sessões (AS, RS, TS e YS). A freqüência cardíaca (FC), pressão arterial sistólica (PAS) e diastólica (PAD) foram mensurados em repouso, durante (a cada 10 minutos) e até 50 minutos de recuperação. Resultados: AS, RS, TS e YS mostrou aumento significativo na FC em relação ao repouso. AS aos 10, 30 e 50 minutos em relação a RS, TS e YS. RS em relação a TS e YS aos 10, 30 e 50 minutos. Não houve diferença significativa entre TS e YS. PAS foi significativamente maior em AS, RS, TS e YS aos 10, 30 e 50 minutos durante a sessão em relação ao repouso. AS foi significativamente maior que RS aos 30 e 50 minutos e maior que TS e YS em 10, 30 e 50 minutos. Não houve diferença significativa na PAD. Para HPE AS, RS e TS reduziram significativamente aos 10, 30 e 50 minutos. YS reduziu aos 50 minutos. Sem diferença na HPE diastólica. Conclusão: TS e YS mostrou-se alternativa segura de exercítação em adultas jovens normotensas, apesar de ter valores mais baixos, promovem comportamento hemodinâmico semelhante ao AS e RS.

Palavras-chave: Tai Ji. Ioga. Exercício. Aptidão Física. Hipotensão.

\section{Introduction}

The ability of exercise to reduce blood pressure (BP) is well established $(1,2)$. Several studies have been conducted to elucidate the relationship between exercise types and magnitude of the hypotensive response after exercise. These studies show that aerobic (AE) (3) and resistance exercises (RE) (4) promote large BP reductions. Concomitantely these classic exercise types, a large portion of the population has sought forms of exercising that allows physical and mental welfare, and among these modalities, Tai-Chi-Chuan and Yoga have received attention $(5,6,7,8)$.

In this way, several studies thathave been conductedshow improvements in cardiorespiratory function and cardiovascular risk reduction, as well asin flexibility and balance $(9,10)$. Regarding cardiovascular risk, according to the guidelines of ACSM and AHA, the practice of aerobic and resistance exercises are recommended to either healthy (2) and cardio paths, due to the phenomenon known as Post Exercise hypotension (PHE) $(1,2)$.

On this point, some factors may influence the reduction of BP after atraining session. A session with static contraction associated to flexibility training during a session can affect hemodynamic responses (11). It is known that muscle fibers recruited activate mechanoreceptors, which elicit cardiovascular adjustments through parasympathetic withdrawal and sympathetic activation (12). Furthermore, small receptors of muscle fiber also react to stretching in humans (13) with a significant impact on the initial heart rate(HR) acceleration. Besides, all of these aspects before-mencioned they are found on a Tai-chichuan and Yoga intervention.

It is possible that cardiovascular responses are great enough to be a concern in exercise programs designed for special populations, such as hypertensive population. Given this, the safety of these "new" exercise types should be tested, as well as whether promotes similar $\mathrm{PEH}$ in comparison to $\mathrm{AE}$ and $\mathrm{RE}$. 
Thus, the aim of this study was to verify the cardiovascular responses during the session and analyse hypotension (PEH) after a Tai Chi Chuan and Yoga sessionin comparison with $\mathrm{AE}$ and REin young adults.

\section{Methods}

Subjects of the study

The study was performed with 14 young female adults (20-25 years). Inclusion criteria: be apparently healthy and previously practicing resistance and aerobic exercises. This research project was approved by the Ethics Committee of the Lauro Wanderley Hospital, of Federal University of Paraíba, under protocol, CAAE- 19876413.0000.5188, according to resolution 196/96 of the National Health Council. The determination of sample size was made as proposed by Eng (14), utilizing the Gpower software 3.1.0 (Franz Faul, Universitat Kiel, Germany). For this, it was adopted a statistical power of 0.80 and analfa error of 0.05 . It was estimated a reduction in systolic BPof $2 \mathrm{mmHg}$ for residual standard deviation of $2 \mathrm{mmHg}$ after resistance exercise (15). As a result, it was determined a minimum of 12 subjects to form the group. All participants were previously informed about the purposes and procedures of the study, and required to sign the Instrument of Consent (IC).

\section{Study Design}

The subjects performed four exercises session: Tai Chi Chuan (TS) andYoga (YS) sessions and two control sessions: Resistance (RS) and Aerobic (AS) sessions, with $48 \mathrm{~h}$ interval between them, randomly determined (www.randomizer.org). Heart rate (HR) and $\mathrm{BP}$ were measured at rest, during and after (in every 10 minutes) exercises session. To measure the subjective perceived exertion we use the Borg scale (16).

\section{Study prepatation}

One week before starting the protocol, participants underwent an adaptation session to TS andYS, with 48 hours of interval between each session. These sessions proved sufficient to all subjects demonstrate autonomy in the movements performed, with a duration of 40 minutes. After a week of adaptation, the subjects performed an anchoring procedureto find the load between 8-12 maximal repetitions of the resistance exercise, in a way that the adequate load was found in a maximal of 3 attempts, following the protocol of Adams et al. (17). All sessions were performed with the objective in maintaina similar intensity between them. After 48 hoursof the Anchoring procedure, it was started the experimental protocols.

\section{Resistance session protocol (RS)}

Composed by three series of 10 repetitions with the load found at the anchoring procedure, cadence of two seconds at eccentric phase and two seconds at concentric phase, with no pause between each of these phases and interval of one minute and thirty seconds between the series. The exercises were selected in a mode that may coincide in the same muscles groups at the exercises protocols TS e YS. We followed Delavier's(18) nomenclature: adduction-abduction; leg extension; front lat pulldowns; squat in a guided bar; straight-arm lat pulldowns; lunges; barbell curls with supinated hands; leg extensions; pushdowns, cable hip abductors. All the resistance protocol was performed at the gym of the Federal University of Paraíba.

\section{Aerobic session protocol (AS)}

Composed by one session in a treadmill (Life Fitness, EUA) of 60 minutes duration. The subjectsmaintain the heart rate between $60-70 \%$ of the maximum heart rate reserve. It was adopted the proposed equation by Karvonen, Kentala e Mustala (19). For the determination of the maximum heart rate, subtracted 220 -age of the each subject. The aerobic protocol was performed at the gym of the Federal University of Paraíba.

\section{Tai Chi Chuan session protocol (TS)}

Composed by one session of the "Yang Style" class with 24 moviments and duration of 60 minutes, following the proposed style by the literature $(20,8)$. The session was constituted by: 
- Periods of concentration - attention on the Tan Tien, region 3-5 $\mathrm{cm}$ below the navel (5 minutes).

- Warming up - Lian Gong exercises emphasize circular movementsof the limbs in aslow and continuous form, associated with breathing and mental concentration. Intensity generally maintained between 6 to 8 of the subjective scale of exertion of Borg (15 minutes).

- Breathing exercise - Therapeutic Chi Kung; breathing exercises with body movements (5 minutes).

- Teaching the bases - with exercise of changing of bases, exchanging the weight bearing between the legs ( 5 minutes).

- Educative teaching - teaching the movements slowly, harmonic and continuously with the body freely associated with breathing and mental concentration (5 minutes).

- Teaching the form - teaching the principal movements of the Tai Chi Chuan form of the Yang style with 24 moviments (5 minutes).

- Trainning the form - repetition of the previously moviments of the Tai Chi Chuan form (10 minutes).

- Concentration - Attention on the Tan Tien, region 3-5 $\mathrm{cm}$ below the navel (5 minutes) of diaphragmatic breathing in a slowly and conscient way.

- Finalization - Corporal energization, with self-massage and energetic unblocking of the meridians through the tapotament technique (5 minutes).

- All the Tai-Chi-Chuan protocol was performed at the Dance saloon at the of the Federal University of Paraíba

Yoga session protocol (YS)

Composed by one session of "Hatha style" classwith nine activities and body movements with duration of 60 minutes, following the proposed protocol by the literature $(6,21)$. The session was constituted by breathing educative exercises:

- Explanation and execution of diaphragmaticbreathing, initial relaxation in Savasana (Posture of the defunct): Lying in supine position, legs and arms apart, palms of the hand facing upward, closed eyes, concentratingon breathing with the objective to be among the wakefulness and sleep state (Meditation) (10 minutes).

- Asanas (Postures)*lying/sitting: postures emphasize the stretching of the lower limbs muscles; standing: postures emphasizestretching of the spine and upper limbs muscles; balance: postures emphasize the corporal balance; strength: postures emphasizing muscular endurance; twisting of the spine: postures emphasizing the spine flexibility (25minutes).

- Pranayamas (breathing exercises): exercises emphasize different ways to breath, including lung retention with full and empty (5minutes).

- Final Relaxation: Savasana(15minutes).

- All asanas should be performed with mental concentration, avoiding musings and focus on breathing and on the worked muscle. The transitions are made consciously avoiding sudden movements.

- All the Yoga protocol were performed at the Dance saloon at the ofthe Federal University of Paraíba.

\section{Cardiovascular measures}

The blood pressure (BP), heart rate (HR) and double product were evaluated in rest, during and after the sessions during 50 minutes of recoveryin TS, YS and AS, and after two exercises of the RS. By the end, $\mathrm{BP}$ and HR were evaluated after exercising at 10, 30 and 50 minutes of recovery, with the subjects in seated position. For the measurement of BP, it was used a sphygmomanometer of Missouri brand (Embu, Brazil), following the recommendations protocols of the VI Brazilian Arterial Hipertension Guidelines (22). The heart rate was analysed by a monitor (Timex SD456 Middlebury, Estados Unidos). Also, to measure the intensity adopted in the sessions, it was used a subjective perceived exertion by the Borg scale (16).

\section{Statistical analysis}

The normality and homogeneity of the data and differences between the standard deviation were verified by Shapiro-Wilk and Levene test, respectively. The data was presented as mean and standard deviation. It was utilized the ANOVA Two-way with Newmankeuls post hoc test for location of the difference within 
the analyses. The minimum detectable difference was calculated for systolic and diastolic blood pressure according to the following formulas from: a) MDD = EPM $x \sqrt{-} 2$; b) EPM $=$ standard deviation $\sqrt{ }^{-} 1$-ICC. ICC (intraclass correlation coefficient) was calculated at the statistical software. For all tests was adopted the value $\mathrm{p}<0.05$ in the interaction. These procedures were performed in the statistical software Instat, 3.06 (GraphPAd software, inc. San Diego, USA).

\section{Results}

The subjects completed the study with no adverse effects. These were normotensive and eutrophic. The previous measures for each session revealed that the HR and BP baselines were similar among the four sessions. This data is shown on Table 1.

Tablel - Anthropometric and hemodynamic characteristics of baseline

\begin{tabular}{|c|c|c|c|c|}
\hline \multicolumn{5}{|c|}{ Subjects $(n=14)$} \\
\hline Age (years) & \multicolumn{4}{|c|}{$22.3 \pm 2.0$} \\
\hline Height (m) & \multicolumn{4}{|c|}{$1.63 \pm 4.0$} \\
\hline Weight (Kg) & \multicolumn{4}{|c|}{$61.7 \pm 6.0$} \\
\hline \multirow[t]{2}{*}{ BMI $\left(\mathrm{Kg} / \mathrm{m}^{2}\right)$} & \multicolumn{4}{|c|}{$23.3 \pm 2.0$} \\
\hline & AS $(n=14)$ & RS $(n=14)$ & TS $(n=14)$ & YS $(n=14)$ \\
\hline SBP (mmHg) & $127.5 \pm 11.0$ & $123.6 \pm 8.0$ & $120.1 \pm 7.6$ & $121.6 \pm 4.0$ \\
\hline DBP (mmHg) & $88.0 \pm 5.6$ & $88.6 \pm 13.7$ & $84.1 \pm 7.6$ & $88.5 \pm 8.7$ \\
\hline HR (bpm) & $74.0 \pm 8.0$ & $71.0 \pm 10.0$ & $76.3 \pm 7.6$ & $74.2 \pm 4.4$ \\
\hline
\end{tabular}

Note: Data presentedas mean and standard deviation. BMI = body mass index; SBP = systolic blood pressure; DBP = diastolic blood pressure; $H R=$ heart rate.

The values of perceived exertion are shown in Figure 1 (Panel A). Significant increase in RS compared to YS at 30 and 50 minutes during exercise. The response of HR is shown on Figure 1 (Panel B). All exercise sessions were significantly elevated compared to rest. In AS, was found greater rise in this variable, with values around $150 \mathrm{bpm}$ and remained stable during all AS. Moreover,their values at 10, 30 and 50 minutes were significantly higher compared to RS, TS and YS. RS showed an increase around 120 bpm, being significantly higher than the TS and YS at 10,30 and 50 minutes. There was no significant difference between TS and YS.
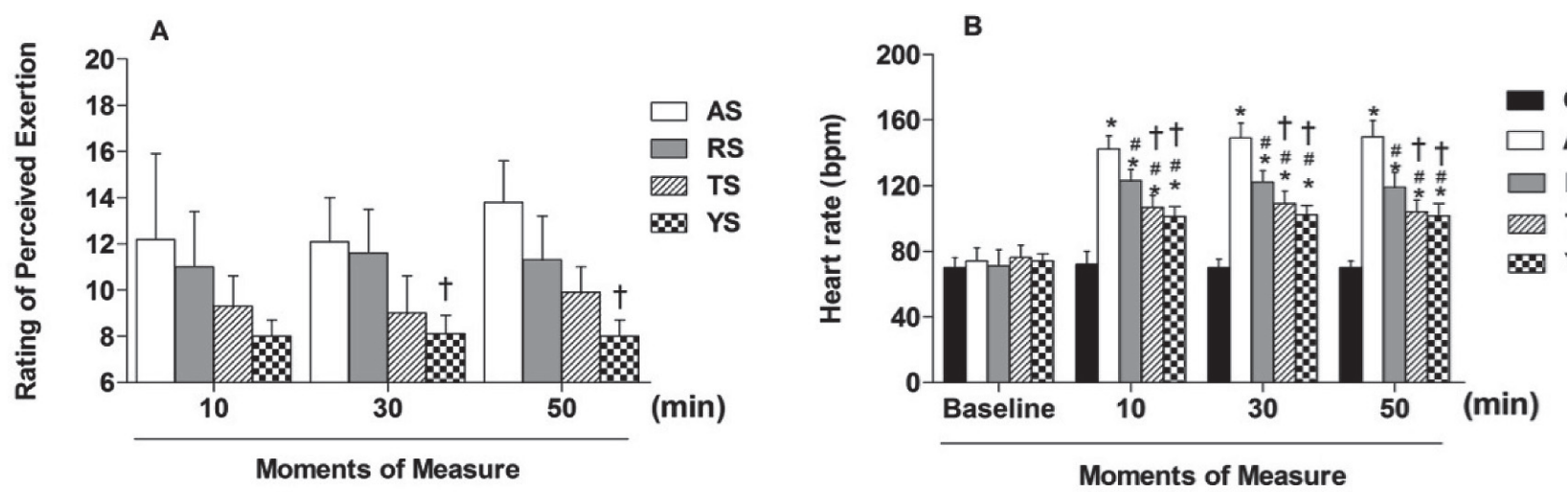

Figure 1 - It shows the values of perceived exertion (Panel A) and heart rate (Panel B) during exercise.Note:*statistical difference between the time of measurement of heart rate during exercise and their resting values. \#difference between the values during exercise compared to aerobic exercise. †Difference between the moments of measures compared to resistance exercise. Significant difference with value of $p<0.05$. 
The values of $\mathrm{BP}$ responses are presented in Figure 2. In Panel A is presented SBP, whichin creased significantly in relation to rest in AS, RS, TS and YS at 10, 30, 50 minutes, with an increase of around 30 to $40 \mathrm{mmHg}$. The greatest changes were seen in AS, with values near to $150 \mathrm{mmHg}$, being significantly higher than the RS at 30 and 50 minutes and greater than TS and YS at 10, 30 and 50 minutes. Regarding DBP (panel B), there was no difference in any of the sessions.
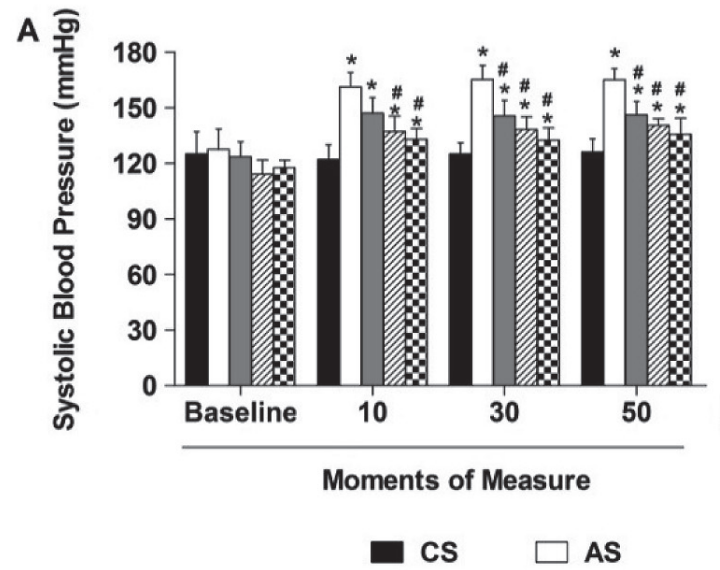

(min)
B

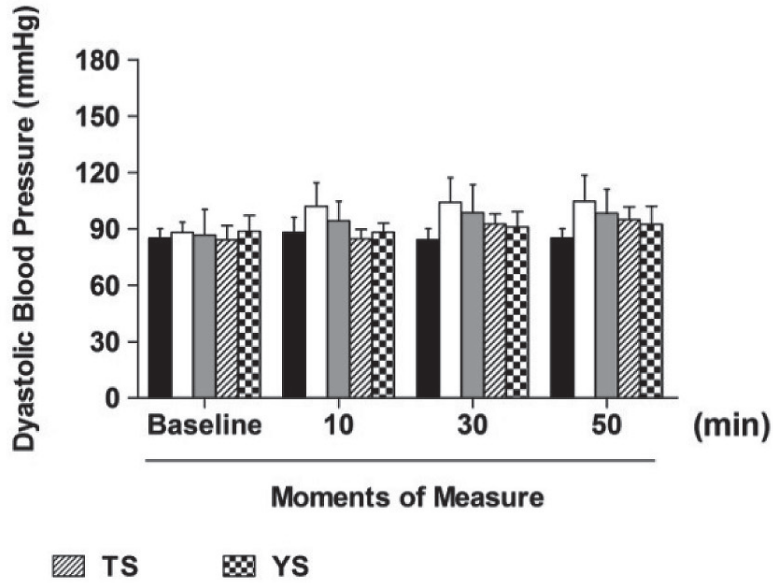

Figure 2 - It shows the values of systolic (Panel A) and diastolic (Panel B) blood pressure during the sessions.

Note:* ${ }^{*}$ statistical difference between the time of measurement of heart rate during exercise, and their resting values. \#Difference between the values during exercise compared to aerobic exercise. Significant difference with value of $p<0.05$.

The double product values are shown in Figure 3. It can be seen that in every session this variable increased from rest at 10, 30 and 50 minutes. The AS showed the highest elevations in relation to all exercise sessions at 10, 30 and 50 minutes, with an increase around $24.000 \mathrm{mmHg} \times \mathrm{bpm}$. Similarly, RS increased when compared to the YS at 10, 30 and 50 minutes, with increase around $17500 \mathrm{mmHg} \times \mathrm{bpm}$.

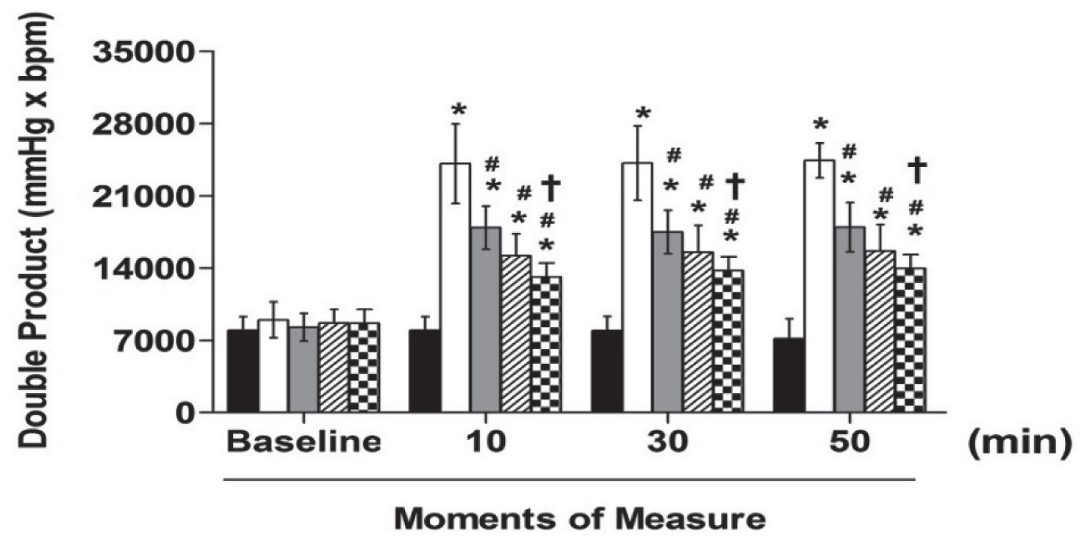

Figure 3 - It shows the values of the double product of the sessions.

Note:*statistical difference between the time of measurement of heart rate during exercise and their resting values \# difference between the values during exercise compared to aerobic exercise. tdifference between the moments of measures compared to resistance exercise. Significant difference on value of $p<0.05$. 
The magnitude of the systolic (Panel A) and diastolic (Painel B) hypotension are shown in Figure 4. All sessions showed significant systolic hypotension (SPEH) compared to rest. The protocol AS shown the greatest systolic reductions in comparison to rest on value near to $12 \mathrm{mmHg}$. It was found that $\mathrm{AS}, \mathrm{RS}$ and TS reduced their values in relation to rest at 10 , 30 and 50 minutes. While YS, reducedat 50 minutes. No significant diastolic hypotension (DPEH) was observed on the sessions, although AS shown the greatest reduction around $6.5 \mathrm{mmHg}$.

\section{A}

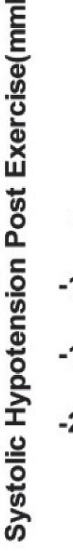

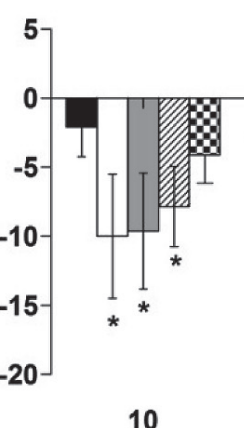

10

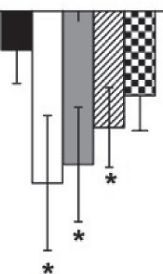

30

Moments of Measure

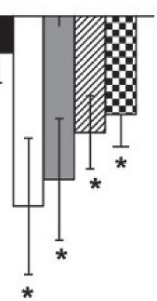

50

(min)

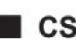

B
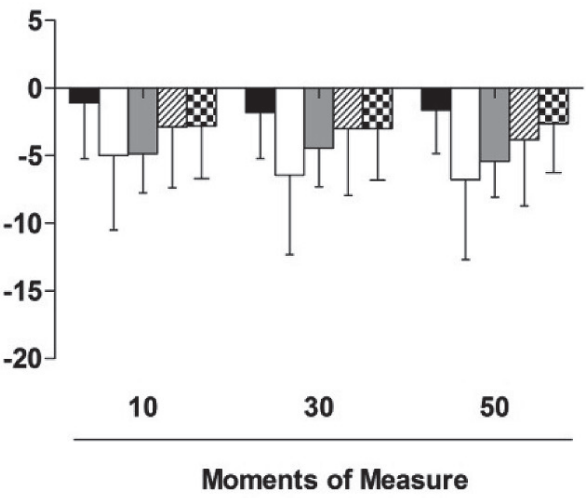

(min)

Figure 4 - It shows the values of post-exercise hypotension of the sessions.

Note:* statistical difference between the time of measurement of heart rate during exercise, and their resting values. Significant difference with value of $p<0.05$.

The ICC: 0.163 found at the statistical software was used to find the MDD for SPEH, which present values of $7 \mathrm{mmHg}$ of minimum detectable difference. The ICC: 0.06 to find MDD for DPEH present values of $7.9 \mathrm{mmHg}$ to detectable clinical differences.

\section{Discussion}

Assuming the hypothesis that the Tai-Chi-Chuan and Yoga interventions may reduce systolic and diastolic blood pressure as much as aerobic and resistance exercises, according to the results of this study in normotensive young adults, one single session of Tai-chi-chuan and Yoga are able to promote PEH and impose an effort on cardiovascular system (as observed by increased BP and DP) but with small changes on perception of exertion (RPE).

Analysing the data from the PEH of the sessions compared acutely, AS in comparison to other sessions showed greater reduction in SBP $(10.0 \pm 4.5 \mathrm{mmHg}$ to $13.8 \pm 4.9 \mathrm{mmHg})$ and diastolic $(5.0 \pm 5.5 \mathrm{mmHg}$ to $6.8 \pm 5.9 \mathrm{mmHg}$ ). Where as, the resistance exercise session was observed significant systolic reductions of $9.6 \pm 4.2$ to $11.1 \pm 4.2 \mathrm{mmHg}$ and diastolic of 4.4 \pm 2.9 to $5.4 \pm 2.6 \mathrm{mmHg}$. Thus, it was found similar values compared in the literature for aerobic (23, $24,3)$ and resistance exercise sessions $(3,4)$. In TS and YS, the present study observed that there were significant systolic hipotension range of $7.8 \pm 2.9$ to $8.4 \pm 2.6 \mathrm{mmHg}$ and diastolic of $2.8 \pm 4.4$ to 3.8 $\pm 4.9 \mathrm{mmHg}$ in the TS post-exercise hypotension. For YS, significant reductions of $4.1 \pm 2.0$ to $7.1 \pm$ $2.3 \mathrm{mmHg}$ of the systolic PEH and $2.6 \pm 3.6$ to $3.0 \pm$ $3.8 \mathrm{mmHg}$ of the diastolic PEH. Corroborating with the acute studies above, which shows that TS and YS can promove similar hypotensive range to aerobic and resistance sessions, and similar values to the results found in the study itself about the hypotension found in the AS and RS (in addition, SPEH from TS and YS shown clinical relevance; $-7 \mathrm{mmHg}$ ). 
Therefore, although was verified a convergence in the literature about the PEH for aerobic and resistance sessions, on our knowledge there are no investigations analyzing acutely if a session of TS and YS would be able to reduce the systolic and diastolic blood pressure, and if these sessions would be similar to aerobic and resistance exercises sessions responses. Thereby, in addition to many positive effects associated to these exercises modalities described in the literature, blood pressure is also a variable that can be modulated.

In this sense, was observed a smaller reduction in systolic and diastolic PEH in relation to AS and RS, they may be considered clinically important. It is known that mininal decreases such as $2 \mathrm{mmHg}$ in blood pressure (less than observed in the present study) are associated with reduction of approximately $6 \%$ in mortality by stroke and $4 \%$ in coronary artery disease (25). Thus, these forms of intervention may be considered as equivalent to use one class of the anti-hypertensive medication (26). If the practitioner does not enjoy perform physical activity such as aerobic or resistance sessions, a single session of Tai Chi Chuan or Yoga presented as an excellent alternative of hypotention promotion. Therefore, being another form of drilling that is capable to provide to the practitioner's BP control.

In fact, the acute analysis of the magnitude of PEH is very important since high BP levels are associated with increased morbidity from all causes (27), but they are also important because they may present a high correlation with reductions in a chronic analysis (1). From previous data, it has beenverified that some studies analyse the cardiovascular changes in Tai-chi Chuan and Yoga chronically. Thornton, Sykes \& Tang (20), submitted 17 healthy women (33-55 years) to Tai chi Chuan (Yang Style) training of three sessions per week for 12 weeks. They observed a significant reduction in SBP of $9.7 \mathrm{mmHg}$ and DBP of $7.5 \mathrm{mmHg}$, while the control group had no significant change. The same by Tsai et al.(24), after three sessions per week during 12 weeks (Yang Style) with 37 subjects (men and women - normotensive e hipertensive level 1), they had a mean reduction in SBP and DBP of $15.6 \mathrm{mmHg}$ and $8.8 \mathrm{mmHg}$. However, the hipertensive population may have helped to provide greater reduction in blood pressure, because this population have higher inotropic response $\mathrm{e}^{3}$.
In Yoga, Chung et al.(28), after Sahaja Yoga meditation with hypertensive and non-hypertensive men and women (between 18 - 65 years), there was a reduction in SBP of $9.4 \mathrm{mmHg}$ and $6.1 \mathrm{mmHg}$, respectively, after the treatment. According to findings from meta-analysis on these effects, the Yoga intervention, similar to this study that proposes the use of posture, breathing and meditation, in a chronic form, may reduce up to $11.8 \mathrm{mmHg}$ for SPB and $7.4 \mathrm{mmHg}$ in DBP after intervention. If we have consolidated answers about the acute analysis, the professionals may modulate the chronic blood pressures responses to be a safe alternative to find better reduces of BP with these two other forms of exercising.

Some possible factors may explain the reduced hypotension in TS and YS sessions when compared to AS and RS. First, the population studied (normotensive). Hypertensive population used on the long-term studies present a greater vascular response, being hyperactive, resulting in a higher hypotension when compared to normotensive (3), and in the present study we used only normotensive. Secondly, as consequence, subjects presenting BP values closest to the base range of normal blood pressure 120 - $129 \mathrm{mmHg}$ (systolic) and80 - $84 \mathrm{mmHg}$ (diastolic) are biased to have smaller magnitudes of hypotension post-exercise compared to those with higher BP values (hypertensives) (22). Whereas our volunteers showed SBP at rest with values of $120.1 \pm 7.6$ e $121.6 \pm 4.0 \mathrm{mmHg}$ in TS and YS respectively in the days of the experiment, may have limited the observation of PEH.

It must be emphasized that some components of the exercise as duration, intensity and type of exercise can influence the PEH. Among these variables, it is assumed that the intensity is one that has a greater influence in acute and chronic exercise responses as well as the risk of their practice $(29,30)$. Thereby, the HR was analized during the entire session as a form to measure the heart effort. It was found the AS and RS intensity remained with values of $71-75 \%$ and $60-62 \%$ of the maximum heart rate, respectively. Futhermore, when analyzing the double product (HRvs SBP), during the sessions, the AS had the highest values, followed by RS. Unlike the sessions that use movements of relaxation during the protocol, the intensity range between $52-55 \%$ in TS and a stable average range of $51 \%$ of the maximum heart rate in YS, which may possibly have influenced their 
hypotensive magnitude. About the double product of TS and YS with lower magnitude values, also it was presented significantly difference compared to the AS and RS, in some moments of measurement.

Still on intensity, knowing the useful tool of The Rating of Perceived Exertion (RPE) that provides a global quantification of an individual's effort or fatigue, considering physiological, psychological, and performance factors (16). RPE may be an important modifier of what a person does versus what the person can do during certain protocol of exercise. The impact of interventions on participation may be influenced by a patient's perception of the ability to exercise. Thus, if TS and YS are perceived to be effortful, then an adult may limit physical activity for recreation and promotion of good health. In TS e YS was observed the lower values, another time.Thereby, overall aspect shave shown that TS and YS sessions proposals have not reached the same level of intensity as AS and RS. Nevertheless, even with an inferior intensity of the myocardium and lower perceived effort to AS and RS, because it is the characteristic of these sessions, the hypotensive magnitude of TS and YS showed significant differences in relation to rest and general hemodynamics similarly with the consolidated interventions in the literature, aerobic and resistance exercises.

Finally, in the present study, the only session style used of Tai Chi Chuan was Yang style and in Yoga was the Hatha style. Future studies can be performed to analyze the cardiovascular changes in different populations and practitioners in many styles of practice of theses types of exercises. Better explaining these factors to become a more safe and useful tool not only to practitioners, but also for professionals at this area that will propose the intervention to the general population and in special cases of diseases.

\section{Conclusion}

Therefore, although Tai Chi Chuan and/or Yoga session did not reduce as much as an aerobic and resistance session, they can be used as a safe alternative of exercising in the normotensive young adult woman population, by promoting during and after session, a similar hemodynamic response in comparison to the compared sessions.

\section{References}

1. Brum PC, Forjaz CLM, Tinucci T, Negrão CE. Adaptações agudas e crônicas do exercício físico no sistema cardiovascular. Rev Paul Educ Fis. 2004;18:21-31.

2. Garber CED, Bryan B, Michael RD, Barry AF, Michael JL, I-Min L, et al. American College of Sports Medicine position stand. Quantity and quality of exercise for developing and maintaining cardiorespiratory, musculoskeletal, and neuromotor fitness in apparently healthy adults: guidance for prescribing exercise. Med Sci Sports Exerc. 2011;43(7):1334-59.

3. Cardoso JRCG, Gomides RS, Queiroz AC, Pinto LG, da Silveira Lobo F, Tinucci T, et al. Acute and chronic effects of aerobic and resistance exercise on ambulatory blood pressure. Clinics. 2010;65(3):317-25.

4. Brito AF, Alves NF, Araújo AS, Gonçalves MC, Silva AS. Active intervals between sets of resistance exercises potentiate the magnitude of postexercise hypotension in elderly hypertensive women. J Strength Cond Res. 2011;25(11):3129-36.

5. Ecclestone NA, Myers AM, Paterson DH. Tracking older participants of twelve physical activity classes over a three-year period. J Aging Phys Act. 1998;6:70-82.

6. Alves AS, Baptista MR, Dantas EHM. Os efeitos da prática do yoga sobre a capacidade física e autonomia funcional em idosas. Fit Perf J. 2006;5(4):243-9.

7. Gloria YY, Wang C, Peter MW, Peter MW, Russell SP. The effect of taichi Exercise on blood pressure: A systematic Reviem. J Cardiopulm Rehabil Prev. 2008;29(3):152-60.

8. Gloria YY, Ellen PM, Peter MW, Lynne WS, Malissa JW, Daniel F,et al. Taichi Exercise in patients with chronicheart failure. Arch Intern Med. 2011;17(8):750-7.

9. Lai JS, Lan C, Wong MK, Teng SH. Twoyears trends in cardiorespiratory function among older Tai Chi Chuan Practitioners and sedentary subjects. J Am Geriatr Soc. 1995;43(11):1222-7.

10. Ramesh LB, Rama P, Vempati BNYS, Raj KY, Rooma BR, Vani G, et al. A brief but comprehensive lifestyle education program based on yoga reduces risk factors for cardiovascular disease and diabetes mellitus. J Altern Complement Med.2005;11(2):267-74. 
11. Foster KL, Higham TE, Williams CD, Salcedo MK, Irving TC, Regnier M, et al. Length curve across gait mechanics in humans. J Appl Physiol (1985).2014;86(1):1445-57.

12. Drew RC, Bell MPD, White MJ. Modulation of spontaneous baroreflex control of heart rate and indexes of vagal tone by passive calf muscle stretch during graded metaboreflex activation in humans. J Appl Physiol (1985). 2008;104(3):716-23.

13. Hayes SG, Kindig AE,Kaufman MP. Comparison between the effect of static contraction and tendon stretch on the discharge of group III and IV muscle afferents. J Appl Physiol (1985).2005;99(5):1891-6.

14. Eng J. Sample Size Estimation: How Many Individuals Should Be Studied? J Radiol. 2003;227(2):309-13.

15. Rezk CC, Marrache RC, Tinucci T, Mion D, Forjaz CL. Postresistance exercise hypotension, hemodynamics, and heart rate variability: influence of exercise intensity. Eur J Appl Physiol. 2006;98(1):105-12.

16. Borg G. Escala de Borg para a Dor e o Esforço Percebido. 1st ed. São Paulo: Manole; 2000. Portuguese.

17. Adams JK, Ann MS, Kerry LB, Joe MB. Safety of Maximal Power, Strength, and Endurance Testing in Older African American Women. J Strength Cond Res. 2000;14(3):254-60.

18. Delavier F. Guia dos Movimentos de Musculação. Abordagem Anatômica. São Paulo: Manole; 2006. Portuguese.

19. Karvonen MJ, Kentala E, MustalaO. The effects of training on heart rate: a longitudinal study. Ann Med Exp Biol Fenn. 1957;35(3):307-15.

20. Thornton WE, Sykes KS, Tang WK. Health benefits of Taichi exercise: Improved balance and blood pressure in middle-age women. Health Promot Int. 2004;19(1):33-8.

21. Kim Y, LeeJ, Yang, JH. Effects of Hatha Yoga Exercise on Body Composition, Serum Lipids, and Health-Related Fitness of Obese Middle-Aged Women. Life Sci. 2011;21(4):521-8.

22. Nobre F. VI Diretrizes Brasileiras de Hipertensão. Arq Bras Cardiol. 2010;95(supl.1):1-53.
23. Brandao RMU, Alves MJ, Braga AM, Teixeira OT, Barretto AC, Krieger EM, et al.Postexercise blood pressure reduction in elderly hypertensive patients. J Am Coll Cardiol. 2002;39(4):676-82.

24. Tsai J, Wei-hsin W, Paul C,Li-jung L, Chia-huei W, Brian T,et al. The benefial effects of Tai Chi Chuan on blood pressure and lipid profile and anxiety status in a radomized controllet trial. J Altern Complement Med. 2003;9(5):747-54.

25. Chobanian AV, Bakris LB, Black HR, Cushman WC, Green LA, Izzo JL, et al. The national high blood pressure education program coordinating committee. The Seventh Report of the Joint National Committee on Prevention, Detection, Evaluation, and Treatment of High Blood Pressure: the JNC 7 Report. JAMA. 2003;289(19):2560-72.

26. Baster T, Baster-Brooks C. Exercise and hypertension. AustFam Physician. 2005;34(6):419-24.

27. Hagins M, States R, Selfe T, Innes K. Effectiveness of Yoga for Hypertension: Systematic Review and Meta-Analysis. Evid Based Complement Alternat Med. 2013;2013:649836.doi: 10.1155/2013/649836.

28. Chung SC, Brooks MM, Rai M, Balk JL, Rai S. Effect of Sahaja yoga meditation on qualite of life, anxiety, and blood pressure control. J Altern Complement Med. 2012;18(6):589-96.

29. American College of Sports Medicine. ACSM's Guidelines for Exercise Testing and Prescription. 7th ed. Baltimore (MD): Lippincott Williams and Wilkins; 2006. English.

30. Forjaz CLM, Rezk CC, Cardoso JRCG,Tinucci T. Exercícios resistidos e sistema cardiovascular. In: Negrão CE, Barretto ACP. Cardiologia do exercício: do atleta ao cardiopata. São Paulo: Manole; 2006. p. 272-85. Portuguese.

Received in 09/30/2014

Recebido em 30/09/2014

Approved in 10/19/2015

Aprovado em 19/10/2015 